\title{
A Rare Case of Acquired Hemophilia, Presenting with Postpartum Hemorrhage
}

\author{
Keni Begendi N*, Kaynar L, Eser B, Ünal A and \\ Çetin M \\ Department of Hematology, Erciyes University, Turkey \\ *Corresponding author: Keni Begendi N, Department \\ of Hematology, Faculty of Medicine, Erciyes University, \\ Erciyes Transplantation Center, Turkey
}

Received: October 03, 2018; Accepted: October 26, 2018; Published: November 02, 2018

\section{Introduction}

Acquired Hemophilia A (AHA) is a rare but serious bleeding disorder caused by autoantibody (inhibitory) against factor 8 (FVIII). The incidence of the disease is increasing with age, and is seen between $9-15 / 1,000,000$ over 65 years of the age, while it is about $0.3 / 1,000,000$ per year under 65 years of the age. The patient and his family usually do not have any known bleeding diathesis [1,2]. The disease is idiopathic in $40-50 \%$ of the cases, while many etiological factors play a role in the remainder. The main etiological factors according to frequency can be listed as; autoimmune diseases, malignancies (solid tumors, hematological neoplasm's), pregnancy, especially in the postpartum period, drugs, vaccination and respiratory system diseases [1,2]. AHA presenting with postpartum hemorrhage constitutes $6-21 \%$ of the all cases [3].

Patients may present with bleeding in the skin, soft tissue, digestive system, or urogenital system, and long-term bleeding after surgery. The clinic is not correlated with FVIII level and inhibitory titer. If there is a new hemorrhage in a person with a normal hemostasis system, or in a case of isolated Partial Thromboplastin time (aPTZ) prolongation without bleeding, the acquired factor deficiencies should be examined [2].

The main cornerstones of treatment are bleeding control, inhibitor eradication and treatment of the underlying disease [4]. FVIII-bypassing agents (recombinant factor 7 (r FVIIa), activated Prothrombin Complex Concentrates (aPCC) are effective in acute bleeding control and are recommended for the first-line treatment [5]. For the purpose of inhibitor eradication, steroids, cyclophosphamide, azathioprine, rituximab, and other immunosuppressive drugs are used and successful results are obtained. For complete response in the eradication of inhibitor; it is aimed that the inhibitor titer $<0.6$ Bethesda Unit (BU) and FVIII activity $>50 \%$ [2]. In life-threatening situations, immunoadsorption and plasmapheresis can be used for inhibitor elimination [6-8].

Postpartum AHA, compared to acquired haemophilias due to other causes; it has a better prognosis with lower mortality rates (0-6\%) and higher complete remission rates $(77-86 \%)[9,10]$. Spontaneous remissions are also reported, but there is a risk of recurrence in other pregnancies $[8,10]$.

\section{Case Presentation}

A 27 years old and 39 weeks pregnant woman was admitted to the obstetrics gynecology clinic in June 2016. Approximately 20 units of erythrocyte suspension and 10 units of fresh frozen plasma were given to the patient because of postpartum menorrhagia and hypermenorrhea. In laboratory tests performed for bleeding, aPTZ was prolonged with $83 \mathrm{sec}$. (n: 20-36 sec.), while in vitro bleeding time and Von Willebrand Factor (VWF) levels were normal. In Hemogram examination; leukocyte $\left(10^{3} / \mu \mathrm{L}\right): 10,000$, hemoglobin ( $\mathrm{gr} /$ $\mathrm{dL}): 6.9$ and platelet $\left(10^{3} / \mu \mathrm{L}\right): 325,000$ seen. FVIII activity for isolated a PTZ prolongation was found to be $<0.4 \%$ and FVIII inhibitory titer was too high to be measured.

Firstly, for bleeding control, rFVIIa was administered at $2^{\star} 100 \mathrm{IU} / \mathrm{kg}$ for 3 days. The patient's vaginal bleeding was controlled with rFVIIa support. On the other hand, oral steroid $1 \mathrm{mg} / \mathrm{kg} /$ day (60mg) was started. One week later, on the test results leukocyte: 11.300, hemoglobin: $11 \mathrm{gr} / \mathrm{dL}$, platelet: 108.000 and aPTZ: $38 \mathrm{sec}$. Were observed and the patient was discharged with $32 \mathrm{mg}$ methyl prednisolone treatment. After 1month, in the laboratory aPTZ: 45 sec, FVIII: $1.4 \%$ and FVIII inhibitory: low titer positive (1.1 Bethesda Unit (BU)) were seen. Steroid dose was reduced to $16 \mathrm{mg}$. The steroid dose was gradually decreased and discontinued at the end of the third month.

In September 2016, the patient presented with spontaneous ecchymotic lesions in the lower extremity, aPTZ: $64 \mathrm{sec}$, FVIII: $0.6 \%$ and FVIII inhibitory titer: $3 \mathrm{BU}$ were observed and $375 \mathrm{mg} / \mathrm{m}^{2}$ weekly rituximab treatment was planned. After the approval of the rituximab from the Ministry of Health, the patient was given 4 weeks of treatment with the interruption of lactation. In December 2016 the patient who did not have any complaints was found to have complete response with aPTZ: $32 \mathrm{sec}$, FVIII: $58 \%$ and FVIII inhibitory: negative results. On October 18, 2017 the patient's second healthy baby was delivered vaginally without any complications. Factor VIII level was normal, aPTZ: $27 \mathrm{sec}$. and inhibitory level was negative in postpartum examinations.

\section{Discussion}

AHA; is a rare but serious bleeding disorder with high morbidity and mortality rates. In the presence of delay in diagnosis, insufficient treatment and complications, mortality rates of up to $22 \%$ are reported [11]. Early diagnosis and treatment is life saving.

Postpartum AHA is usually seen in the first pregnancy and usually reported within the first 4 months of the postpartum period. Spontaneous remissions have been reported in patients with low inhibitory titer [12]. In patients presenting with high inhibitory titer, the inhibitor can persist for years and lead to the development of autoimmune diseases therefore, the elimination of inhibitors with immunosuppressive agents is important [13]. 
For inhibitor elimination, steroid may be administered as a single agent or in combination with other immunosuppressants (cyclophosphamide, azathioprine, rituximab, etc). Rituximab is often preferred and recommended because of good tolerability, less incidence of side effects, rapid and high remission rates in both first-line treatment and the absence of response with other immunosuppressors.

In the studies, rituximab was frequently administered once a week between 1-4 cycles and remission was achieved in about 2-3 weeks, while it was obtained in about 39-48 weeks with other immunosuppressives $[14,15]$. Stasi et al. showed that response to rituximab treatment was obtained after 3 weeks (between 3-12 weeks) [16]. Recurrences of approximately $20 \%$ after immunosuppressive therapy are usually seen about 7-9 months after the end of treatment (1 week-14 months) [17].

In our patient, steroid was preferred as a single drug in the first line treatment for inhibitor elimination which is too high to be measured. After two months of treatment, almost complete response was obtained. The steroid dose was gradually decreased and discontinued at the end of the third month. Unfortunately nearly three weeks after the discontinuation of the drug, the patient presented with ecchymosis in the lower extremities and the recurrence of the disease was observed by the detection of the inhibitor again. A total of 4 courses of rituximab therapy for inhibitor eradication in relapsed disease were applied and a complete response was obtained at the end of the treatment. Ten months after the end of the treatment, the patient performed her second healthy birth. The clinical and laboratory findings of the patient were stable and no recurrence of the disease has been observed in her follow-up till now.

In the treatment of postpartum AHA due to pregnancy, rituximab is a successful treatment option with fewer side effects, higher response rates and long-term remission. Rituximab is preferred and recommended in order to protect the patient from cytotoxic drugs as a first-line therapy agent and in patients with high inhibitory titers who cannot respond to other immunosuppressors as a second-line therapy agent.

\section{References}

1. Franchini M, Mannucci PM. Acquired haemophilia A: a 2013 update. Thromb Haemost. 2013; 110: 1114-1120.

2. M Demir, A Ünüvar. Diagnosis and Treatment of Acquired HemophiliaTurkish Hematology Association Hemophilia, Diagnosis and Treatment Guidelines. 2011; 3: 27-32.
3. Tengborn L, Baudo $F$, Huth-Kühne $A$, Knoebl $P$, Lévesque $H$, Marco $P$, et al. Pregnancy-associated acquired haemophilia $A$ : results from the European Acquired Haemophilia (EACH2) 2012 registry. BJOG. 2012; 119: 1529-1537.

4. Collins PW. Therapeutic challenges in acquired factor VIII deficiency. Hematology Am Soc. 2012; 369-374.

5. Franchini M, Lippi G, Franchi M. The use of recombinant activeted factor VII in obstetric and gynaecological haemorrhage. BJOG. 2007; 114: 8-15.

6. Collins P, Baudo F, Knoebl P, Lévesque H, Nemes L, Pellegrini F, et al. $\mathrm{EACH} 2$ registry collaborators. Immunosuppression for acquired hemophilia A: results from the European Acquired Haemophilia Registry. Blood. 2012; 120: 47-55.

7. Franchini M, Mannucci PM. Inhibitor eradication with rituximab in haemophilia: where do we stand? Br J Haematol. 2014; 165: 600-608.

8. Carlo Bonfanti, Silvia Crestani, Francesco Frattini, Cinsia Sissa, Massimo Franchini. Role of rituximab in the treatment of acquired haemophilia A; Blood Transfus. 2015; 13: 396-400.

9. Delgado J, Jimenez-Yuste V, Hernandez-Navarro F, Villar A. Acquired haemophilia: review and meta-analysis focused on therapy and prognostic factors. Br J Haematol. 2003; 121: 21-35.

10. Michiels JJ. Acquired hemophilia A in women post-partum: clinical manifestations, diagnosis and treatment. Clin Appl Thromb Haemost. 2000; 6: 82-86.

11. Collins PW. Management of acquired hemophilia A. J Thromb Haemost. 2011; 9: 226-235

12. Franchini M. Postpartum Factor VIII Inhibitors. Am J Hematol. 2006; 81: 768773.

13. Franchini M, Gandini G, Paolantonio TD, Mariani G. Acquired Haemophilia A: A concise review. Am J Hematol. 2005; 80: 55-63.

14. Maillard H, Launay D, Hachulla E, Jenny Goudemand, Marc Lambert, Sandrine Morell-Dubois, et al. Rituximab in postpartum-related acquired hemophilia. Am J Med. 2006; 119: 86-88.

15. Santaro C, Rago A, Biondo F, De Propris MS, De Vellis A, Guarini A, et al. Efficacy of rituximab treatment in postpartum acquired haemophilia $A$. Haemophilia. 2008; 14: 147-149.

16. Stasi R, Brunetti M, Stipa E, Amadori S. Selective B-cell depletion with rituximab for the treatment of patients with acquired haemophilia. Blood. 2004; 103: 4424-4428.

17. Collins P, Hirsch S, Baglin TP, Dolan G, Hanley J, Makris M, et al. UK Haemophilia Centre Doctors' Organisation. Acquired haemophilia A in the United Kingdom: a 2-year national surveillance study by the United Kingdom Haemophilia Centre Doctors' Organisation. Blood. 2007; 109: 1870-1877.
Ann Hematol Oncol - Volume 5 Issue 7 - 2018 ISSN : 2375-7965 | www.austinpublishinggroup.com Keni Begendi et al. (C) All rights are reserved
Citation: Keni Begendi N, Kaynar L, Eser B, Ünal A and Cetin M. A Rare Case of Acquired Hemophilia, Presenting with Postpartum Hemorrhage. Ann Hematol Oncol. 2018; 5(7): 1218. 